\title{
ACTIVE IMAGINATION: \\ FOR PSYCHOLOGY WITHOUT BORDERS
}

Lyra, S.R.

Our time is different from the preceding ones by the rediscovery of psychic channels buried in earlier cultures, where the psyche was no more than a metaphysical system. A present, we can no longer do without this knowledge, denying or omitting the obscure powers of unconscious realities, even though such ideal of the Middle Ages has been replaced by the ideal of material and physical safety, general well-being and humanitarianism. Powers that cannot be inserted in the rational order of the world, but that act generating and mobilizing symptoms both in the singular individual as in the social environment where such individual lives, make us realize that this ideal also seems to mean an increasing threat and an even worse catastrophe.

Given this situation what could the future hold for us? It seems that the psychological interest of our time expects something that the external world cannot give, and even religions that could come from within are nothing more than inventories of an outer world. Can Brazil, a country of Latin America contribute to forging a psychological future in common with the European Community?

We will present here Active Imagination as the new possibility to be shared with psychologists and psychiatrists from all over the world, who are the only ones worldwide authorized to use the method. Our proposa is to describe this technique, as it is being developed in the South of Brazil, and to indicate the ways to access it. We believe this way we can offer something unprecedented and effective for the treatment of the Individual and, consequently, of the environment where such an individual lives, based on a unique experience and not only on assumptions. For example:
THE ACTIVE IMAGINATION TECHNIQUE FOR BRUXISM TREATMENT

WWW.WASET.ORG - RESEACH of BRUXISM in 2013 PRESENTED in BERLIN/ GERMANY.

SJÖGREN'S SYNDROME AND THE TECHNIQUE OF ACTIVE IMAGINATION. YALE UNIVERSITY-USA. In 2015.

\section{What is the active imagination?}

Is a technique generally used in Jungian circles and very little known, however, widely covered by the ICHTHYS Analytical Psychology Institute of Curitiba, Paraná, southern Brazil, by PhD.

The method developed by c.g. Jung, was systematized by Robert Johnson through his book: INNER WORK: the key to the Kingdom within, ed. Mercuryo, 1989.

This is a unique work that promotes a dialogue between the conscious and the unconscious to the assimilation of the unconscious by conscience, and, what is sought is to find hidden emotions in the images and the images hidden in the emotions. After which, through the dialectic method the place to be reached will be especially, the transformation of the symptoms.

It is my hypothesis that, because it is a tool used by Analytical Psychology, it can became known world to open up new perspectives for the treatment of the psyche of individuals and consequently, their relationship with society Our first research in Brazil was made official by CONEP (research with human beings).
The Active Imagination Technique for Bruxism Treatment was to evaluate the effect of the Active Imagination technique for the treatment of bruxism, and this project was, appreciated and approved by the Ethics Committee for research on Human Beings (CAAE: 05619512.9.0000.0109). It was concluded that $66 \%$ of the volunteers had the painful symptoms, difficulty in opening the mouth and chewing pain reduced after a session of active imagination of ' 60 (sixty minutes). Many of the participants also abandoned the use of muscle relaxant effects accessory after this session only. Unprecedented, bruxism is now part of the diseases that have possibility to be cured what was unlike beforehand. Seeking confirmation for such research, a reassessment was conducted 18 months after for the same people submitted previously to this research and the results were amazing and very promising.

The same article was submitted in the IX Ibero American Congress of Psychology in Lisbon-Portugal on 09 September 2014.

And in this way, the Active Imagination technique became an open field for a number of searches that can be performed, with some in progress.

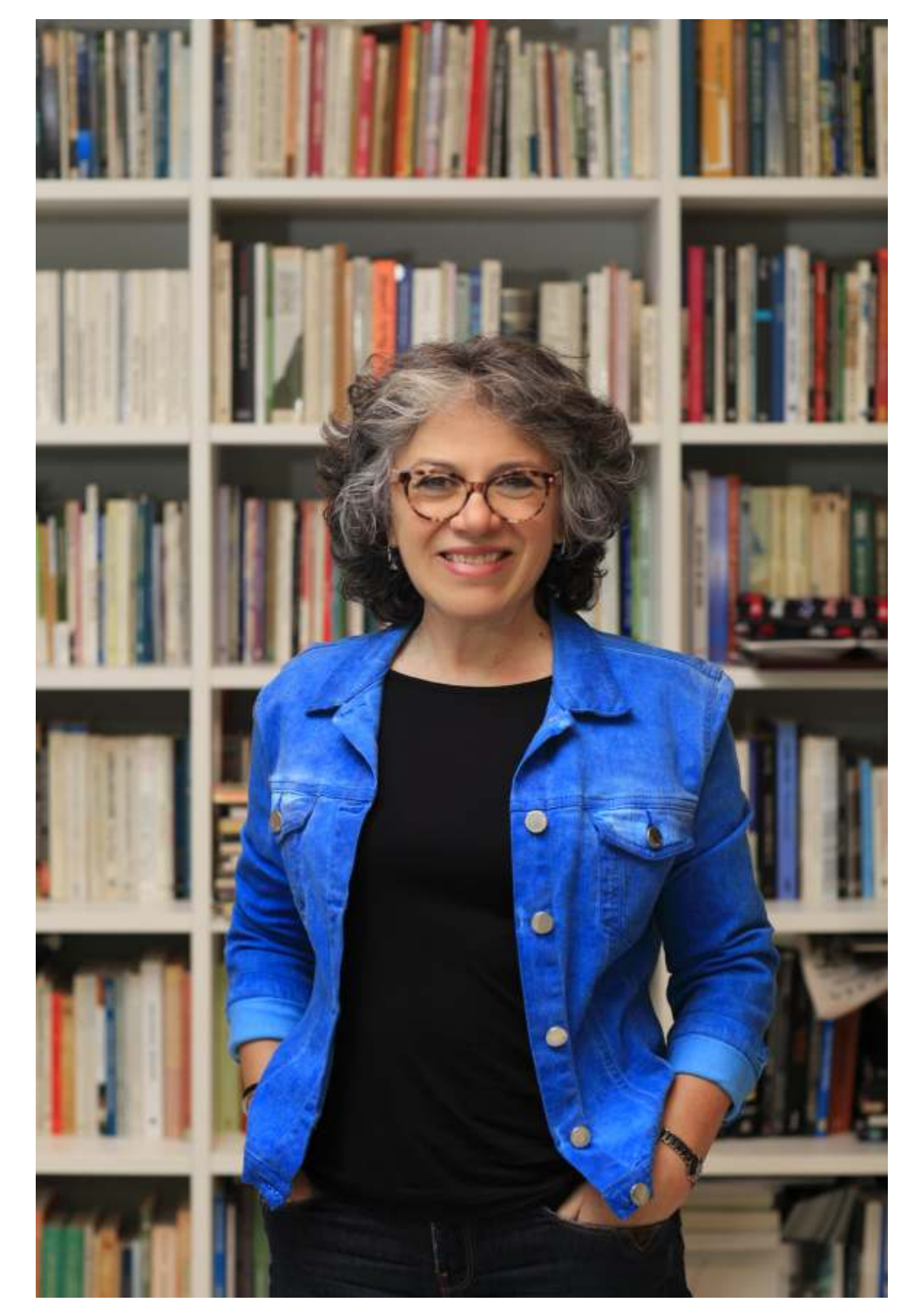

Lyra, S.R. Psychologist; Master of Philosophy; PhD in Religious Studies; PostDoctoral in Philosophy; Jungian Analyst Member of the International Association for Analytical Psychology; Director of Ichthys Institute of Analytical Psychology; Author of several books.

(c) 2019 Copyright

www.sonialyra.com.br contato@sonialyra.com.br. 